\title{
Increased radiosensitivity of colorectal tumors with intra-tumoral injection of low dose of gold nanoparticles
}

This article was published in the following Dove Press journal:

International Journal of Nanomedicine

12 October 2016

Number of times this article has been viewed

\author{
Minghan Shi' \\ Benoit Paquette' \\ Thititip Thippayamontri' \\ Louis Gendron² \\ Brigitte Guérin' \\ Léon Sanche' \\ 'Department of Nuclear Medicine and \\ Radiobiology, Center for Research \\ in Radiotherapy, ${ }^{2}$ Department of \\ Pharmacology-Physiology, University \\ of Sherbrooke, Sherbrooke, \\ QC, Canada
}

\begin{abstract}
The potential of gold nanoparticles (GNPs) as radiosensitizers for the treatment of malignant tumors has been limited by the large quantities of GNPs that must be administered and the requirement for low-energy X-ray irradiation to optimize radiosensitization. In this study, we enhance the radiosensitivity of HCT116 human colorectal cells with tiopronin-coated GNPs (Tio-GNPs) combined with a low-energy X-ray (26 keV effective energy) source, similar to the Papillon 50 clinical irradiator used for topical irradiation of rectal tumors. Sensitizer enhancement ratios of 1.48 and 1.69 were measured in vitro, when the HCT116 cells were incubated with $0.1 \mathrm{mg} / \mathrm{mL}$ and $0.25 \mathrm{mg} / \mathrm{mL}$ of Tio-GNPs, respectively. In nude mice bearing the HCT116 tumor, intra-tumoral (IT) injection of Tio-GNPs allowed a 94 times higher quantity of Tio-GNPs to accumulate than was possible by intravenous injection and facilitated a significant tumor response. The time following irradiation, for tumors growing to four times their initial tumor volume (4Td) was 54 days for the IT injection of $366.3 \mu \mathrm{g}$ of Tio-GNPs plus $10 \mathrm{~Gy}$, compared to 37 days with radiation alone $(P=0.0018)$. Conversely, no significant improvement was obtained when GNPs were injected intravenously before tumor irradiation $(P=0.6547)$. In conclusion, IT injection of Tio-GNPs combined with low-energy X-rays can significantly reduce the growth of colorectal tumors.
\end{abstract}

Keywords: gold nanoparticles, colorectal cancer, mice, X-ray, radiation enhancement

\section{Introduction}

High-Z nanomaterials have gained much attention for the radiation dose enhancement properties associated with their strong absorption of ionizing radiation and propensity to generate copious amounts of secondary electrons. In the past decade, while a substantial number of studies have investigated radiosensitization by gold nanoparticles (GNPs) in vitro, little has been published on their radiosensitizing properties in vivo. ${ }^{1-10}$ Tumor growth retardation or improvements in animal survival were observed only at very high doses of GNPs $(\sim 2 \mathrm{~g} / \mathrm{kg})$ administered intravenously (IV) prior to tumor irradiation..$^{5,8}$ With much lower doses, ie, $13.5 \mathrm{mg}$ of GNPs injected IV, no tumor growth retardation was measured in mice bearing murine mammary carcinoma. ${ }^{9}$

The need to treat with such high doses of GNP renders problematic transition from animal studies into the clinic. Moreover, GNPs injected IV accumulate largely in liver and kidneys and when administered orally accumulate mostly in spleen, liver, stomach, small intestine, and kidneys. ${ }^{11,12}$ Studies of acute toxicity, particularly liver toxicity, indicate that to be nontoxic the size of GNPs should be controlled to be smaller than $4.8 \mathrm{~nm} .{ }^{13-16}$ It is also unclear whether GNPs can cause long-term adverse effects, since no such study has been performed. Moreover, since GNPs are expensive,
Correspondence: Benoit Paquette Department of Nuclear Medicine and Radiobiology, Center for Research in Radiobiology, Faculty of Medicine and Health Science, Université de Sherbrooke, 300I, I2e Avenue North, Sherbrooke, QC, Canada, JIH 5N4

Tel + I 819346 II I0x74767

Fax +I 8195645442

Email benoit.paquette@usherbrooke.ca

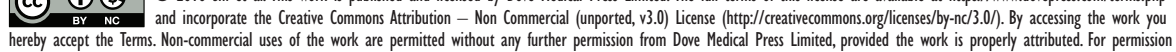
for commercial use of this work, please see paragraphs 4.2 and 5 of our Terms (https://www.dovepress.com/terms.php). 
patients' treatment costs are another factor that must be considered. Considering these aspects, it is thus appropriate to ask whether it is possible to decrease the dose of GNPs and retain their radiosensitizing effect.

To overcome these obstacles, Bobyk et $\mathrm{al}^{10}$ injected GNPs directly into the F98 glioma tumor implanted in the brain of Fischer rats by intra-tumoral (IT) convection-enhanced delivery (CED). This procedure increased the tumoral uptake of GNPs, and consequently only $250 \mu \mathrm{g}$ per rat (0.96-1.14 mg GNPs per kg) was necessary to significantly improve animal survival. The optimal radiosensitizing effect of GNPs in soft tissue is expected to be observed with an X-ray irradiation energy of $\sim 80 \mathrm{keV} \cdot{ }^{17}$ However, the mean free path of $80 \mathrm{keV}$ photons is $<35 \mathrm{~mm}$, which is too short to treat efficiently most brain tumors in humans. ${ }^{5}$ Nevertheless, the work of Bobyk et $\mathrm{al}^{10}$ clearly showed that, for superficial tumors, efficient radiosensitization can be achieved by combining GNPs with low-energy X-ray irradiation.

The current study explores the treatment with GNPs of colorectal cancers, which are the fourth most common cancer and the second most common cause of cancer death. ${ }^{18}$ In its early stage, colorectal cancer can be treated by topical irradiation with the Papillon 50 irradiator. However, topical $\mathrm{X}$-ray therapy alone may not be sufficient, since the long-term control of patients is $90 \%$ for T1N0 stage, $80 \%$ for T2N0 stage, and only $50 \%$ for early T3 stage. ${ }^{19}$ The mean energy of this X-ray source is $26.5 \mathrm{keV}$, and the maximum energy is $50 \mathrm{keV}$, which provides a $50 \%$ depth of the absorbed dose at $\sim 6.5-7 \mathrm{~mm} .{ }^{19}$ To further increase the efficiency of the Papillon 50 technique, we propose to combine it with the endoscopic IT injection of GNPs. ${ }^{20-23}$ In the current study, male nu/nu mice bearing HCT116 human colorectal tumor were treated by IT injection of tiopronin-coated GNPs (Tio-GNPs) and then irradiated with an X-ray source, which has a similar energy spectrum compared to that of the Papillon 50 X-ray unit (Figure 1). ${ }^{24,25}$

The ligand that coats the GNP must be carefully chosen. Long ligands can attenuate the low-energy photoelectrons emitted from the GNPs after radiation, which could then lead to a considerable decrease in any radioenhancement effect. ${ }^{26}$ The short ligand citrate is frequently used to prepare citrate-coated GNPs. ${ }^{7,27}$ However, such GNPs will aggregate in solution when their concentration exceeds only a few $100 \mu \mathrm{g} / \mathrm{mL}$. Since only a small volume of GNPs-containing solution can be injected IT, this tendency to aggregate prevents high concentrations of GNPs from reaching the tumor. To overcome these limitations, Tio-GNPs were chosen because 1) the short length of the tiopronin ligand ( $9.15 \AA$, calculated by Accelrys Materials Studio) minimizes absorption in the coating of photoelectrons emitted from the
A

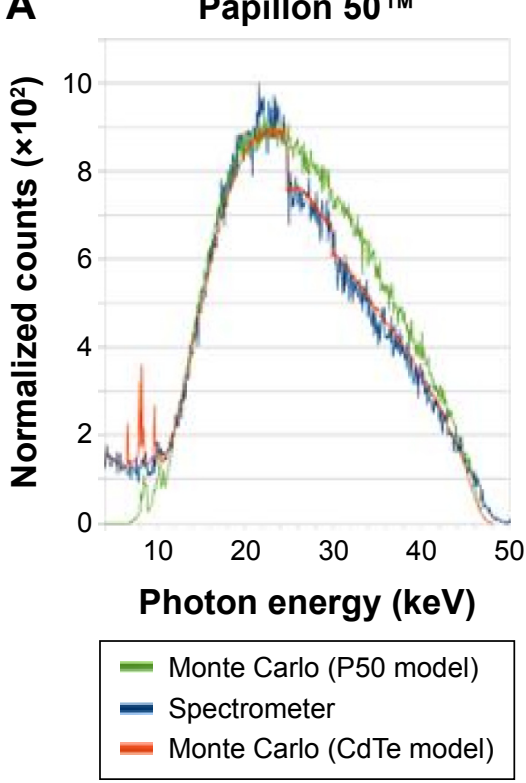

B

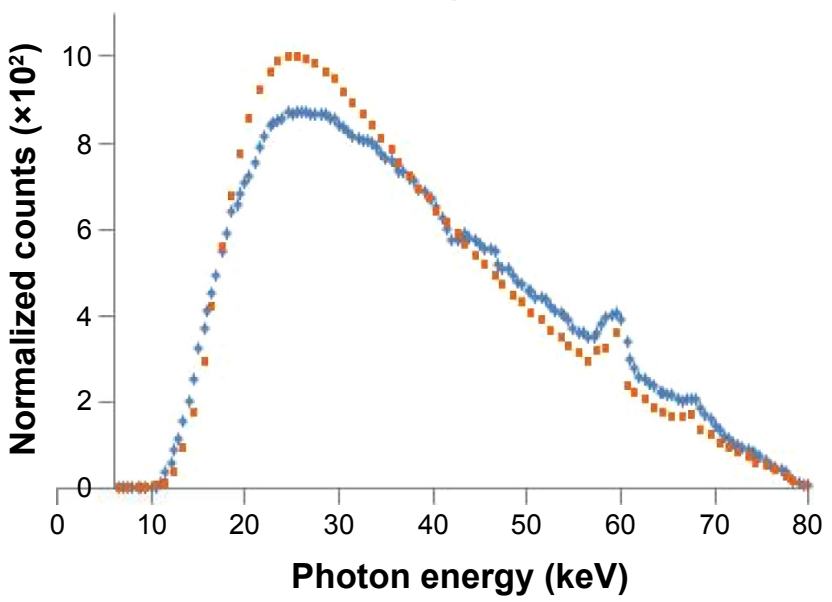

* Measured

Simulated

Figure I Comparison between the X-ray beam spectra from a Papillon 50 system used for the treatment of colorectal cancer and the Therapax source used in this study. Notes: (A) Papillon 50 X-ray beam spectra simulated with PENELOPE for the Papillon 50 geometry (green curve), simulated with Papillon 50 geometry including the CdTe detector geometry (red curve), and measured using CdTe detector (blue curve) (modified from Radiat Phys Chem, 8I/6, Croce O, Hachem S, Franchisseur E, Marcie S, Gerard J, Bordy J, Contact radiotherapy using a $50 \mathrm{kV}$ X-ray system: Evaluation of relative dose distribution with the Monte Carlo code PENELOPE and comparison with measurements., 609-6I7, Copyright (2012), with permission from Elsevier. ${ }^{25}$ ). (B) Therapax SXT I50 X-ray beam spectra simulated with SpectrumGUI software and measured using CdTe detector for beam effective energies of $26 \mathrm{keV}$ (modified from Lessard et al. ${ }^{24}$ ).

Abbreviation: CdTe, cadmium telluride. 
gold and 2) their higher stability against aggregation permits the use of higher GNP concentrations. ${ }^{28}$ Radiosensitization by Tio-GNPs was first assessed in vitro in HCT116 human colorectal cancer cells, and the induction of double-strand breaks (DSBs) was measured. The antitumor potential of Tio-GNPs was then studied in HCT116 human colorectal tumor-bearing nude mice.

\section{Materials and methods Preparation of Tio-GNPs}

Tio-GNPs were prepared as described by Templeton et al. ${ }^{28}$ Briefly, $0.1033 \mathrm{~g}$ ( $0.27 \mathrm{mmol}, 1$ equiv) of gold(III) chloride trihydrate and $0.1267 \mathrm{~g}(0.80 \mathrm{mmol}, 3$ equiv) of tiopronin (Sigma-Aldrich Co., St Louis, MO, USA) were codissolved in $11.67 \mathrm{~mL}$ of $6: 1$ methanol:acetic acid. Then, $0.2 \mathrm{~g}$ (5.33 mmol, 20 equiv) of sodium borohydride (SigmaAldrich Co.) was added and stirred for 45 minutes. Next, the solvent was removed under vacuum and purified by dialysis for 72 hours (Spectra/Por CE, MWCO 10 000; Spectrum ${ }^{\circledR}$ Laboratories, Inc., Rancho Dominguez, CA, USA). Tio-GNPs were lyophilized and stored at room temperature until being used. GNPs concentrations were measured by inductively coupled plasma mass spectrometry (ICP-MS, ELAN DRC-II; PerkinElmer Inc., Waltham, MA, USA).

\section{Cellular uptake of Tio-GNPs}

HCT116 cells at $70 \%$ confluence were incubated with $0.25 \mathrm{mg} / \mathrm{mL}$ of Tio-GNPs in minimum essential medium (MEM) without fetal bovine serum for 4-48 hours. Cells were washed twice with phosphate-buffered saline (PBS), trypsinized, and counted. Then, the cells were digested in $2 \mathrm{~mL}$ of $30 \%$ hydrogen peroxide and $2 \mathrm{~mL}$ of $70 \%$ nitric acid, and the concentration of gold was determined by ICP-MS analysis. $^{29}$

\section{Subcellular localization of Tio-GNPs}

HCT 116 cells were incubated with $0.25 \mathrm{mg} / \mathrm{mL}$ of Tio-GNPs for 24 hours, and then rinsed with $0.1 \mathrm{M}$ phosphate buffer, fixed with ice-cold $2 \%$ paraformaldehyde for 20 minutes, and washed twice with $0.1 \mathrm{M}$ phosphate buffer. The samples were kept in $0.2 \mathrm{M}$ citrate buffer, $\mathrm{pH}$ 7.4. To detect GNPs with more efficiency, their size was increased using the protocol of Silver Enhancer Kit for Microscopy (Cytodiagnostics, Burlington, ON, Canada). ${ }^{30}$ Afterward, the cells were washed twice with citrate buffer, rinsed with $0.1 \mathrm{M}$ phosphate buffer, and stained with $1 \%$ osmium tetroxide for 90 minutes. The samples were then dehydrated with increasing ethanol concentrations and covered with Epon 812 resin mixture
(Electron Microscopy Sciences, Hornby, ON, Canada) twice within 3 hours. The resin was allowed to polymerize at $60^{\circ} \mathrm{C}$ for 48 hours. Sections of $80 \mathrm{~nm}$ were prepared using a Leica Ultracut UCT Ultramicrotome (Leica Microsystems, Wetzlar, Germany), contrasted with uranyl acetate (Electron Microscopy Sciences), and visualized under Hitachi H-7500 transmission electron spectroscope.

\section{Cytotoxicity of Tio-GNPs assessed with a clonogenic assay}

Clonogenic assay was performed as described by Tippayamontri et $\mathrm{al}^{31}$ with some modifications. Briefly, 1,000 HCT116 cells were plated in $100 \mathrm{~mm}$ Petri dishes for 24 hours. For the group receiving only radiation, doses ranging from $1 \mathrm{~Gy}$ to $10 \mathrm{~Gy}$ of $\mathrm{X}$-rays were delivered to the cells. The X-ray source was operated at $4 \mathrm{~mA}, 80 \mathrm{kV}$, with an average energy of $26 \mathrm{keV}$ (Pantak Therapax 3 series). For the group treated only with Tio-GNPs, increasing concentrations of Tio-GNPs were incubated with the HCT116 cells for 24 hours. The combination of Tio-GNPs plus radiation was performed by adding either $0.1 \mathrm{mg} / \mathrm{mL}$ or $0.25 \mathrm{mg} / \mathrm{mL}$ of Tio-GNPs to the MEM without fetal bovine serum for 24 hours and then irradiating (with 1-10 Gy). During the 7-day incubation, the MEM was not renewed to prevent the detachment of cells from colonies that might then produce new colonies leading to erroneous results. After 7 days of incubation in completed MEM, colonies were fixed, stained, and counted.

\section{Analysis of DNA DSBs by immunofluorescence assay for $\gamma \mathrm{H} 2 \mathrm{~A}$.X}

HCT116 cells were plated on coverslips and then treated 24 hours later with either $0.25 \mathrm{mg} / \mathrm{mL}$ of GNPs alone, 2 Gy alone, or $0.25 \mathrm{mg} / \mathrm{mL}$ of GNPs plus $2 \mathrm{~Gy}$ radiation. One hour after treatment, cells were fixed in 4\% paraformaldehyde, permeabilized by $0.1 \%$ of Triton X-100, quenched by $1 \mathrm{mM}$ glycine, and blocked by $10 \%$ dried powdered milk in PBS. Then, primary antibody phospho-histone H2A.X (Ser139) (20E3) rabbit mAb (Cell Signaling Technology, Inc. Beverly, MA, USA) 1:400 in 10\% dried powdered milk in PBS was incubated with cells overnight at $4^{\circ} \mathrm{C}$. Afterward secondary antibody anti-rabbit $\operatorname{IgG}(\mathrm{H}+\mathrm{L}), \mathrm{F}\left(\mathrm{ab}^{\prime}\right) 2$ fragment (Alexa Fluor $^{\circledR} 488$ Conjugate; Cell Signaling Technology, Inc.) $1: 1,000$ in $10 \%$ dried powdered milk in PBS was incubated with cells for 2 hours in a humidified chamber, followed by the incubation of $286 \mathrm{nM} \mathrm{4',6-diamidino-2-phenylindole}$ at room temperature for 15 minutes. Then, the cells were rinsed and viewed under an Olympus FLUOVIEW FV1000 
confocal laser scanning microscope (Olympus Corporation, Tokyo, Japan). Foci were counted by ImageJ. ${ }^{32}$

\section{Animal model}

Male nu/nu nude mice at the age of 4-6 weeks were purchased from Charles River Laboratory (Saint-Constant, QC, Canada). HCT116 cells $\left(2 \times 10^{6} / 100 \mu \mathrm{L}\right.$ MEM) were inoculated subcutaneously into each rear flank. Tumor size was first measured once tumors reached a volume of $\sim 100 \mathrm{~mm}^{3}$, and subsequently, continued twice weekly. Tumor volumes were calculated with the following formula:

$$
V\left(\mathrm{~mm}^{3}\right)=\pi / 6 \times L \times W^{2}
$$

where $L$ and $W$ are the length and width of tumor diameters, respectively. All the procedures were approved by the Université de Sherbrooke Animal Care and Use Committee (protocol number 235-10B). Guidelines of the Canadian Council on Animal Care were followed (ad libitum access to food and water, controlled room temperature and relative humidity, $12 \mathrm{~h}$ light/dark cycle). Mice were anesthetized by intraperitoneal injection of ketamine/xylazine $(87 / 13 \mu \mathrm{g} / \mu \mathrm{L})$ at $1 \mu \mathrm{L} / \mathrm{g}$ for all procedures.

\section{Antitumor effect}

Mice were randomized into six groups (IV Tio-GNPs, IV Tio-GNPs + radiation therapy (RT), IT Tio-GNPs, IT Tio-GNPs + RT, IT PBS, and IT PBS + RT) with minimum of five mice per group. Tio-GNPs were delivered either IV (732.6 $\mu \mathrm{g} / 10 \mu \mathrm{L})$ or IT $(366.3 \mu \mathrm{g} / 10 \mu \mathrm{L}$ in each tumor). A radiation dose of $10 \mathrm{~Gy}$ was delivered 8 hours later with the $\mathrm{X}$-ray unit at an effective energy of $26 \mathrm{keV}$. The tumor was placed in the center of a $1 \mathrm{~cm}$-diameter X-ray applicator.

\section{Tumor uptake of Tio-GNPs}

Once tumor volumes reached $100 \mathrm{~mm}^{3}$, Tio-GNPs were injected in mice bearing two tumors, either IV at its maximal relevant concentration $(732.6 \mu \mathrm{g} / 10 \mu \mathrm{L})$ or IT at $366.3 \mu \mathrm{g} / 10 \mu \mathrm{L}$ into each tumor. Eight hours later, the mice were euthanized, tumors were extracted, weighed, digested, and the amounts of gold were determined by ICP-MS analysis.

\section{Statistical analysis}

From survival fraction curves, sensitizer enhancement ratio (SER) was calculated by dividing the area under the curve, which represents mean inactivation dose of the radiation group, by results of the radiation plus Tio-GNPs group. ${ }^{33}$ For the in vivo study, the time required for the tumor volume to increase by a factor 4 (4Td) was chosen as a defining characteristic of each experiment. They were plotted by Kaplan-Meier curve, and log-rank test to analyze the differences between groups. One-way ANOVA was performed to analyze the cellular uptake of Tio-GNPs at different incubation times and the number of $\gamma \mathrm{H} 2 \mathrm{~A} . \mathrm{X}$ foci. Two-way ANOVA was performed to analyze the cell survival obtained by clonogenic assays. Unpaired $t$-test was performed to analyze the tumor uptakes of Tio-GNPs. All of statistical analyses were performed using Graphpad Prism 6 (GraphPad Software, Inc., La Jolla, CA, USA) except for the in vitro survival fraction curve, which was fitted by OriginPro 2015 using a Levenberg-Marquardt iteration algorithm with unequal weighting of each data point (OriginLab Corp., Northampton, MA, USA). $P<0.05$ was considered significantly different. Clonogenic assays were performed in triplicate, three times. For the in vivo tumor growth study, a minimum of five tumors were followed. All other studies were carried out in triplicates.

\section{Results \\ Characterization of Tio-GNPs}

Tio-GNPs dissolved in water were dried on transmission electron microscopy grids and visualized under transmission electron microscopy to determine the distribution of their diameters (Figure 2A). Diameters ranged from $1.21 \mathrm{~nm}$ to $5.41 \mathrm{~nm}$, for a mean diameter of $2.77 \pm 0.69 \mathrm{~nm}$ (Figure 2B). The size of Tio-GNPs remained constant when remeasured in the MEM at concentrations of $0.1 \mathrm{mg} / \mathrm{mL}$ and $0.25 \mathrm{mg} / \mathrm{mL}$ (Figure S1).

\section{Localization and uptake of Tio-GNPs in HCTI I 6 cells}

All Tio-GNPs were located in the cytoplasm and appeared in vesicle-like structures, suggesting that Tio-GNPs are taken up by cells through an endocytosis-dependent mechanism (Figure 3A). ${ }^{34}$ The cellular uptake of Tio-GNPs increased to a maximum at 8 hours $(33 \pm 7.7 \mathrm{ng} \mathrm{Au} / 1,000$ cells), then gradually decreased to reach significantly lower concentration at 48 hours (Figure 3B). An 8-hour interval between the introduction of Tio-GNPs and radiation was then chosen in subsequent in vitro assays.

\section{In vitro radiosensitization of $\mathrm{HCT}$ I 6 cells by Tio-GNPs}

Clonogenic assays were performed to determine the radioenhancement induced by Tio-GNPs in HCT116 cells (Figure 4). Tio-GNPs alone were not toxic at the concentrations used. A significant reduction in cell survival was found when 


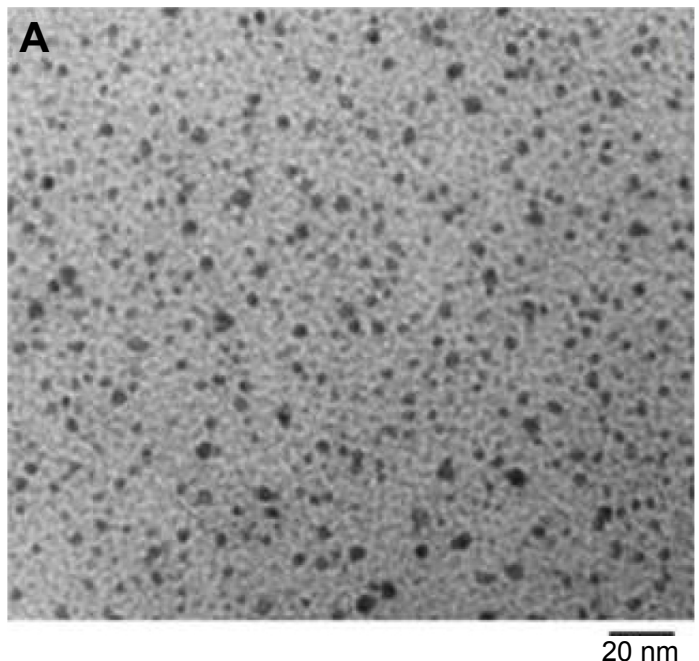

$\overline{20 \mathrm{~nm}}$

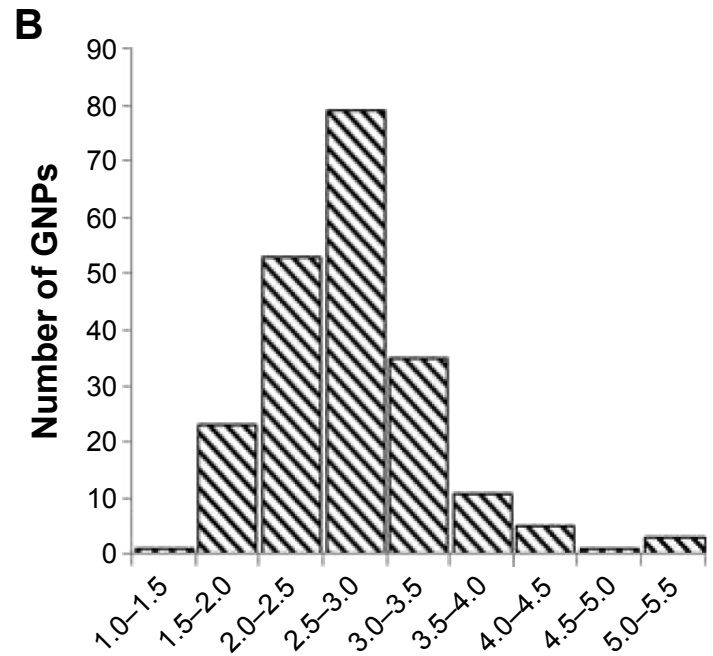

Size $(\mathrm{nm})$

Figure 2 Characterization of Tio-GNPs.

Notes: (A) TEM image of Tio-GNPs (scale bar $=20 \mathrm{~nm}$ ). (B) Diameter distribution of Tio-GNPs measured using TEM. Magnification: I00,000×.

Abbreviations: TEM, transmission electron microscopy; Tio-GNPs, tiopronin-coated gold nanoparticles.

Tio-GNPs were combined with 1-4 Gy of radiation. Tio-GNPs incubated at $0.1 \mathrm{mg} / \mathrm{mL}$ and $0.25 \mathrm{mg} / \mathrm{mL}$ resulted in an SER of 1.48 and 1.69 , respectively.

\section{Assessment of DSBs in HCTII 6 cells}

The level of the DSBs marker, $\gamma \mathrm{H} 2 \mathrm{~A} . \mathrm{X}$, was measured to determine whether the dose-enhancing effect of Tio-GNPs was associated with an increase in this type of DNA lesion in HCT116 cells (Figure 5). No significant induction of $\gamma \mathrm{H} 2 \mathrm{~A} . \mathrm{X}$ was found when Tio-GNPs at $0.25 \mathrm{mg} / \mathrm{mL}$ were incubated without irradiation. As expected, when the HCT116 cells were exposed to $2 \mathrm{~Gy}$, the number of $\gamma \mathrm{H} 2 \mathrm{~A} . \mathrm{X}$ increased by 3.8 -fold compared to the untreated cells (control group: 2.51 $\pm 0.19, \mathrm{n}=397 ; 2$ Gy: 9.44 \pm 0.170 , $\mathrm{n}=672 ; P<0.0001)$, consistent with DSB induction being associated with a reduction in cell survival. However, combining Tio-GNPs with radiation did not correlate with a greater induction of this type of DNA damage (2 Gy: 9.44 $\pm 0.17, \mathrm{n}=672$; Tio-GNPs +2 Gy: 9.53 \pm 0.16 , $\mathrm{n}=842 ; P=0.7)$.
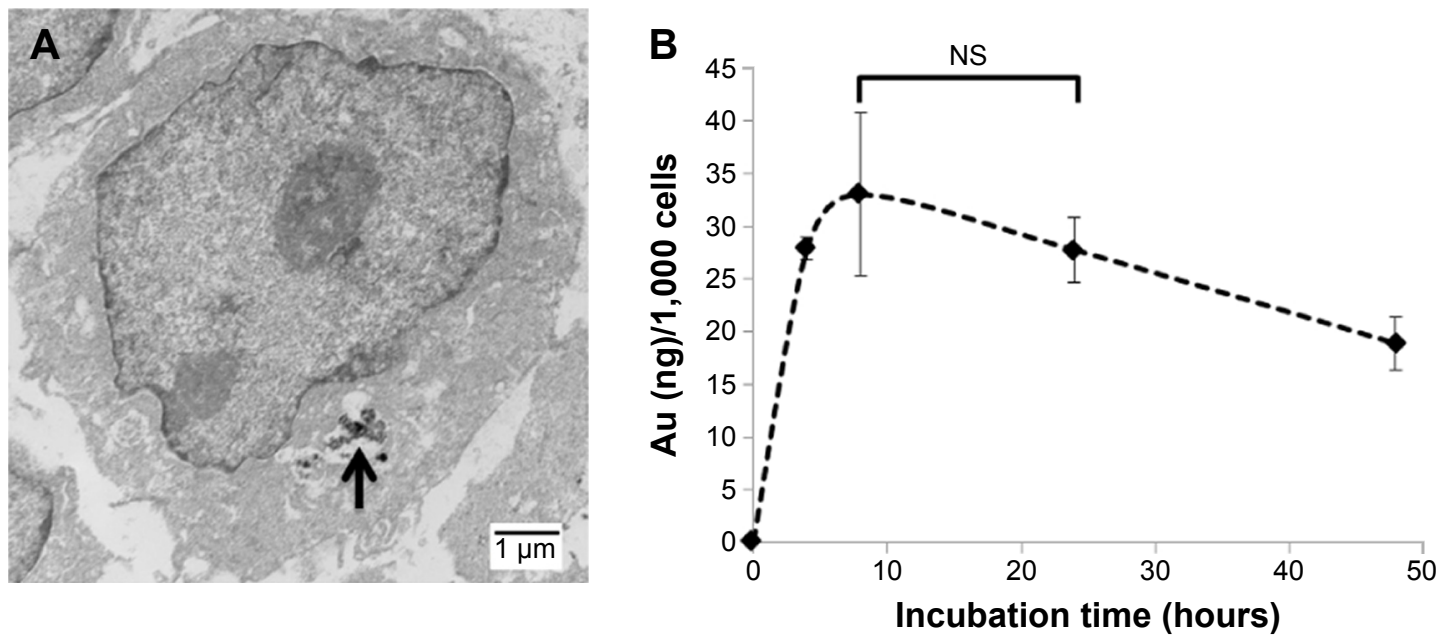

Figure 3 Subcellular localization and cellular uptake of Tio-GNPs.

Notes: (A) TEM image of subcellular localization of Tio-GNPs in HCTII6 cells. Tio-GNPs in the cytoplasm were located in vesicles (black arrow). HCT-II6 cells were incubated with $0.25 \mathrm{mg} / \mathrm{mL}$ of Tio-GNPs for 24 hours. Tio-GNPs were visualized using silver enhancement under TEM (scale bar =I $\mu \mathrm{m}$ ). (B) The uptake of GNPs in HCTII6 cells after different times of incubation ( 0 hour, 4 hours, 8 hours, 24 hours, and 48 hours). HCTI 16 cells were incubated with 0.25 mg/mL of GNPs. Data are expressed as mean \pm SEM. A significant increase in cellular uptake was measured compared to control, at 8 hours, 24 hours, and 48 hours after incubation (One-way ANOVA, 4 hours, $P<0.01$; 8 hours, $P<0.00$ I; 24 hours, $P<0.01$; 48 hours, $P<0.05)$. No significant differences were found after 8 hours and 24 hours of incubation $(P>0.05)$. Magnification: $3,500 \times$. Abbreviations: NS, not significant; SEM, standard error of the mean; TEM, transmission electron microscopy; Tio-GNPs, tiopronin-coated gold nanoparticles. 


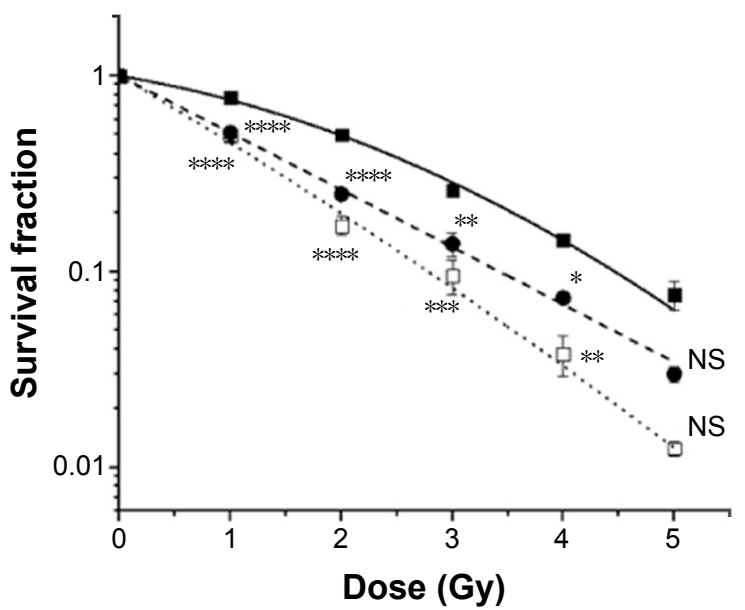

Figure 4 Survival curve of HCTII6 cells treated with (घ) radiation alone $\left(\mathrm{SF}=\mathrm{e}^{\left(-0.217 \mathrm{D}-0.067 \mathrm{D}^{2}\right)}\right.$, adjusted $R^{2}=0.9986,50 \%$ cell survival, LD50 $\left.=\mathrm{I} .98 \mathrm{~Gy}\right),(\bullet)$ Tio-GNPs $0.1 \mathrm{mg} / \mathrm{mL}+$ radiation $\left(\mathrm{SF}=\mathrm{e}^{\left(-0.669 \mathrm{D}-0.001 \mathrm{D}^{2}\right)}\right.$, adjusted $R^{2}=0.988 \mathrm{I}$, LD50 $=1.03 \mathrm{~Gy})$, and $(\square)$ Tio-GNPs $0.25 \mathrm{mg} / \mathrm{mL}+$ radiation $\left(\mathrm{SF}=\mathrm{e}^{\left(-0.767 \mathrm{D}-0.022 \mathrm{D}^{2}\right)}\right.$, adjusted $R^{2}=0.9943$, LD50 $=0.88 \mathrm{~Gy}$ ).

Notes: Results are in response to a Two-way ANOVA. *Significant at $P<0.05$, **significant at $P<0.01$, *** significant at $P<0.001$, ****significant at $P<0.0001$.

Abbreviations: D, dose; NS, not significant; SF, survival fraction; Tio-GNPs, tiopronincoated gold nanoparticles.

\section{Radioenhancement by Tio-GNPs of}

\section{HCTII 6 tumor implanted in nude mice}

The relative efficiency of Tio-GNPs injected IV and IT to increase the radiosensitization was assessed in nude mice implanted with a HCT116 tumor (Figure 6A and B). Tumor growth after IV or IT injection with Tio-GNPs was similar to that of implanted tumors in untreated animals (IT Tio-GNPs vs control, $P=0.3755$; IV Tio-GNPs vs control, $P=0.1106$ ). These results indicate that Tio-GNPs were not toxic under the current experimental conditions.
An irradiation with 10 Gy significantly reduced the tumor growth. The time required to increase by fourfold the initial tumor volume (4Td) was 37 days, ie, 30 days longer than the untreated tumor that reached the $4 \mathrm{Td}$ at a median time of only 7 days. When tumors were injected IV with Tio-GNPs and then irradiated 8 hours later, tumor growth was not significantly slower than that seen for the radiation-alone group (median $4 \mathrm{Td}$ of 32 days, $P=0.6547$ ). A significant radiosensitization was obtained only with IT injection of Tio-GNPs. The tumor growth retardation was then significantly greater ( $4 \mathrm{Td}=54$ days) than that seen in the radiation-alone group $(P=0.0018)$ or when Tio-GNPs were injected IV plus radiation $(P=0.038)$.

\section{Tumor uptake of Tio-GNPs}

The tumor uptake of Tio-GNPs obtained after IV and IT injections was measured at 8 hours. As expected, a significant higher tumor uptake of Tio-GNPs was achieved by IT injection $(496 \pm 106 \mu \mathrm{g} \mathrm{Au} /$ tissue $[\mathrm{g}])$ than by IV injection (5.27 $\pm 1.17 \mu \mathrm{g} \mathrm{Au} / \mathrm{g}$; Figure 6C).

\section{Discussion}

A decade ago, Hainfeld et $\mathrm{al}^{8}$ presented the first animal studies using GNPs as an agent capable of enhancing the radiation dose locally. In the intervening years, the biological effects of different sizes, coatings, and concentrations of GNPs, as well as different methods of delivery and radiation energies, have been investigated. ${ }^{6-8,10,15,33,35}$ In the current study, we carefully chose appropriate experimental parameters based on the previous results: $2.77 \mathrm{~nm}$ Tio-GNPs coated
A
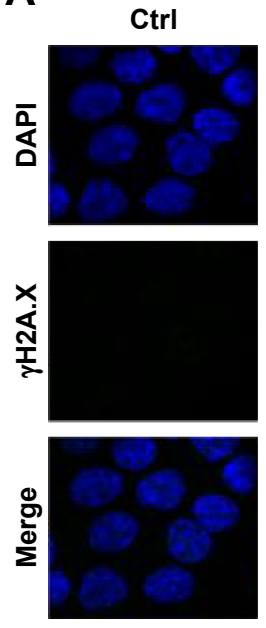

Tio-GNPs alone
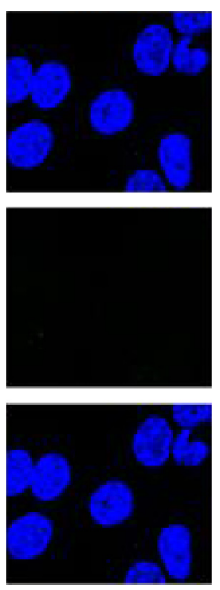
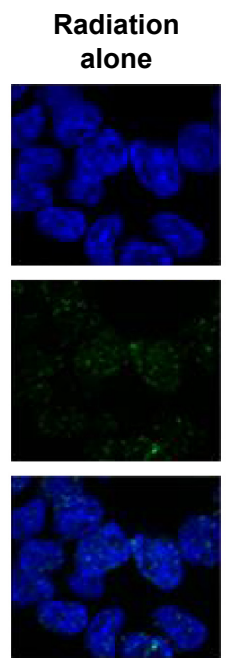

Tio-GNPs + radiation
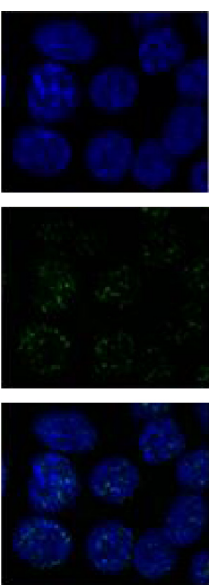

B

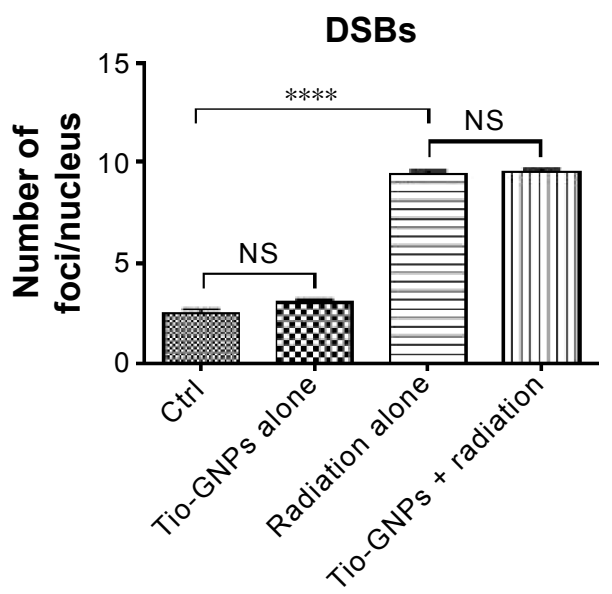

Figure $5 \gamma \mathrm{H} 2 \mathrm{~A} . \mathrm{X}$ immunofluorescence study in HCTII6 cells.

Notes: (A) $\gamma \mathrm{H} 2 \mathrm{~A} . \mathrm{X}$ immunofluorescence from DSBs induced by different treatments. (B) $\gamma \mathrm{H} 2 \mathrm{~A} . \mathrm{X}$ foci of control, Tio-GNPs alone, $\mathrm{X}$-ray alone, and Tio-GNPs + X-ray. Two-way ANOVA was performed to analyze the difference between groups. Results are in response to a One-way ANOVA. **** Significant at $P<0.000 \mathrm{I}$.

Abbreviations: DSBs, double-strand breaks; NS, not significant; Tio-GNPs, tiopronin-coated gold nanoparticles. 
A

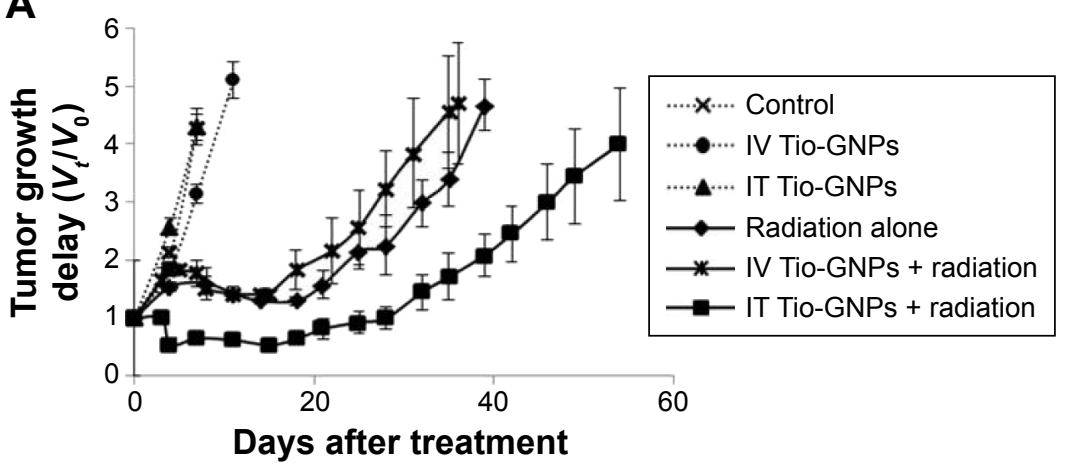

B
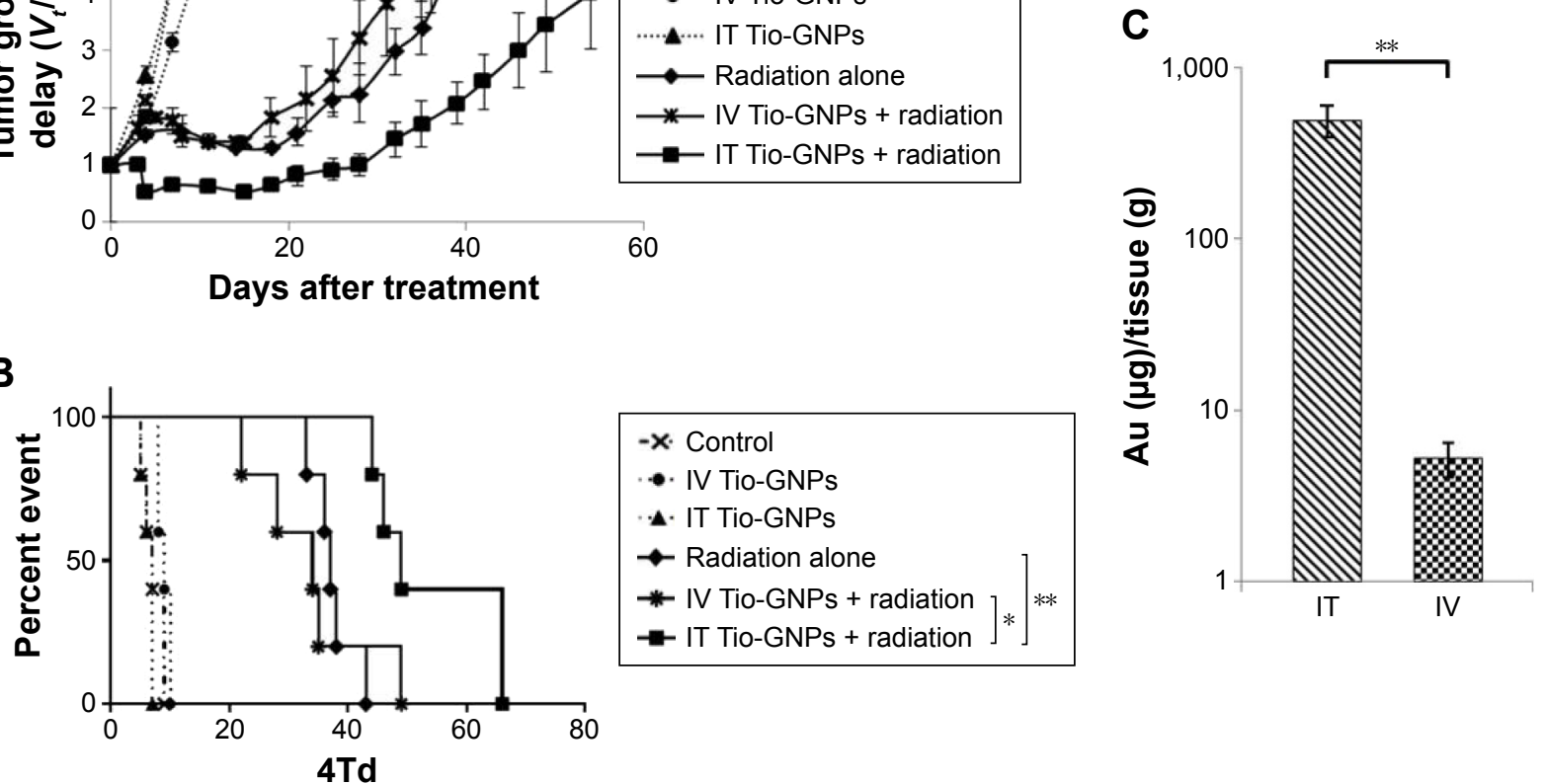

Figure 6 In vivo study of tumor growth delay after different treatments and tumor uptake of Tio-GNPs measured after IV or IT injection.

Notes: (A) The tumor growth delay after the initial treatment of nude mice bearing HCTII6 colorectal tumor with IT PBS, IT Tio-GNPs, IT PBS plus radiation, IT Tio-GNPs plus radiation, and IV Tio-GNPs plus radiation. Tumor growth delay is reported as $V_{t} / V_{0}$ ratio, where $V_{t}$ is the mean tumor volume on a given day during the treatment and $V_{0}$ is the mean tumor volume at the beginning of the treatment. Each symbol represents the mean \pm SEM of the results obtained with at least five tumors. (B) Kaplan-Meier curve of mice whose tumors have reached the 4Td. An event is defined as the tumor size reached four times of its original size (4Td), ( $n=5$ ) (C) Tumor uptake of Tio-GNPs at 8 hours after IT or IV after injecting $20 \mu \mathrm{L}$ at a concentration of $36.63 \mathrm{mg} / \mathrm{mL}$ of Tio-GNPs/rat. Unpaired $t$-test was performed to analyze the difference between tumor uptake of Tio-GNPs by IT and IV injection. Results are in response to a log-rank test. *Significant at $P<0.05$, **Significant at $P<0.0$ I.

Abbreviations: IT, intra-tumoral; IV, intravenous; NS, not significant; PBS, phosphate-buffered saline; Tio-GNPs, tiopronin-coated gold nanoparticles; SEM, standard error of the mean.

with tiopronin which were delivered via the IT route to mice bearing HCT116 colorectal tumors before irradiation with $26 \mathrm{keV}$ effective energy X-rays.

The tiopronin molecule has a length of $\sim 9.15 \AA$. GNPs coated with this short ligand are expected to permit a larger number of damaging low-energy electrons to traverse the coating than would occur with GNPs coated with longer molecules. Low-energy electrons have short thermalization distances, and thus their transmission through the coating is dependent on the length of the ligand. ${ }^{26}$ In the study by Xiao et al, four types of GNPs having ligands of different lengths were dried on DNA films and irradiated with $60 \mathrm{keV}$ electrons. The yields of DNA single-strand breaks and DSBs induced by radiation were found to be roughly inversely proportional to the length of ligands. The DSB yields induced by radiation in the absence or presence of GNPs coated with dithiolated diethylenetriamine pentaacetic acid (DTDTPA) or DTDTPA-Gd were the same. In contrast, irradiation of DNA in the presence of naked GNPs doubled the DSB yields relative to radiation alone. ${ }^{26}$ The concept that some coatings are too thick to allow radiosensitization by photoelectrons is also consistent with the results of Hébert et al, ${ }^{9}$ in which no median survival improvement was observed for irradiation with $150 \mathrm{kVp} 20$ minutes after IV injection of $0.675 \mathrm{~g} / \mathrm{kg}$ DTDTPA-Gd-coated GNPs into mice bearing MC7-L1 murine mammary ductal carcinomas. However, in this latter case, factors other than GNP coating cannot be excluded. In a Monte Carlo simulation study, it was demonstrated that following a single ionizing event from $40 \mathrm{keV}$ primary radiation, $2 \mathrm{~nm}$ GNPs deposit a larger dose per gold atoms in the vicinity of the nanoparticle than do larger GNPs. This implies that Tio-GNPs of $\sim 2 \mathrm{~nm}$ are more effective in inducing a radioenhancement than larger Tio-GNPs. ${ }^{36}$ This result may be explained by the fact that in larger GNPs, it is more likely that Au photoelectrons within the nanoparticle will be inelastically scattered to energies below the vacuum level and thus more likely to stay within the GNP. Inelastically scattered photoelectrons that do escape the GNP core will likely have reduced energy, which further decreases their chances to escape the tiopronin layer. Such computational results are also supported by the work of Misawa and Takahashi, ${ }^{37}$ which studied 5-250 nm-diameter GNPs and 
demonstrated a higher production of reactive oxygen species with smaller size of GNPs. However, Chithrani et $\mathrm{al}^{7}$ demonstrated that among GNPs of diameters $14 \mathrm{~nm}, 50 \mathrm{~nm}$, and $74 \mathrm{~nm}$, the $50 \mathrm{~nm}$ GNPs exhibited the highest radiation enhancement factor, but this was likely due to the higher cellular uptake of the latter GNPs. Similarly, Zhang et al ${ }^{15}$ showed that $12.1 \mathrm{~nm}$ GNPs provided a better tumor growth control compared to the $4.8 \mathrm{~nm}, 27.3 \mathrm{~nm}$, and $46.6 \mathrm{~nm}$ GNPs because of the higher tumor accumulation of the $12.1 \mathrm{~nm}$ GNPs when delivered IV. These points, particularly the Monte Carlo simulation and the reactive oxygen species generation studies, justify our choice of the small $2.77 \mathrm{~nm}$ Tio-GNPs to produce a high local radioenhancement.

Significantly, Tio-GNPs can be produced at very high concentrations. This is an essential factor when applying GNPs to in vivo studies. Indeed, previous studies have shown that large quantities of GNPs $^{5,8-10}$ were necessary to achieve observable CED radioenhancement ${ }^{10}$ in gliomabearing Fischer rats. In this latter study, two doses of GNPs were investigated: $125 \mu \mathrm{g}$ and $250 \mu \mathrm{g}$. The high dose group demonstrated an increased median survival time of 41 days compared to the 35 days of the radiation-alone group $(P=0.05)$, while the low-dose group did not show a significant improvement $(P=0.47)$.

In our in vitro cytotoxicity study, a higher radioenhancement (SER of 1.69) was produced with a dose of $0.25 \mathrm{mg} / \mathrm{mL}$ of Tio-GNPs than was obtained with a dose of $0.1 \mathrm{mg} / \mathrm{mL}$ (SER of 1.48). The yield of DSBs was studied to better identify the mechanisms of radioenhancement. We found that DSB damage did not increase for the GNPs plus radiation group relative to the radiation-alone group. Therefore, this radioenhancement is not related to an increase in DSB damage, but rather to the localization of Tio-GNPs in the cytoplasm (presumably by endocytosis, and the formation of endocytotic vesicles), which is shown in Figure 3. This result supports the hypothesis that radiosensitization can occur without the induction of additional DSBs. Our results are also in accordance with the previous work of Jain et al, ${ }^{33}$ who observed that GNPs enhanced the efficiency of radiotherapy without causing additional DNA damage. Other possible mechanisms such as changes in biological pathways and targeting of hypoxic cells were proposed.

Our in vivo study compares the tumor uptake of GNPs via IV injection to that via IT injection, with tumor growth retardation upon combination with radiation. At 8 hours postinjection, it is clearly shown that for equal quantities of GNPs, IV injection was not able to attain as high a tumor concentration as did IT injection. This is consistent with our results indicating that growth retardation is greater with IT delivery. Furthermore, the IT injection of $366.3 \mu \mathrm{g}$ of GNPs required to observe radiosensitization agrees well with the value of $250 \mu \mathrm{g}$ used in the experiments of Bobyk et al. ${ }^{10}$ These results support the view that the maximum quantity of GNPs that can be delivered IV is not sufficient to reach a concentration in the tumor that could significantly improve the radiosensitivity of HCT116 human colorectal tumor. GNPs can significantly increase radiosensitivity, but only when they accumulate at the high levels obtainable with IT injection.

Other than GNPs, nanomaterials such as hafnium nanoparticles, gadolinium nanoparticles, and titanium nanoparticles are also candidate radiosensitizers, each having their own advantages. ${ }^{38}$ Hafnium oxide nanoparticles are more chemically inert than GNPs and have shown a major radioenhancement effect under Cobalt-60 source activation in HT1080 and A673 mesenchymal tumors and in HCT116 human colorectal tumor xenografted in nude mice. ${ }^{39}$ In that study with HCT116 tumor, IT injection of nanoparticles plus 8 Gy gamma radiation suppressed tumor growth in the measured 25 days, while treatment with radiation alone showed less suppression. In our study with Tio-GNPs, tumors remained at their original size for up to 28 days after treatment. Townley et $\mathrm{al}^{40}$ studied rare earth-doped titania nanoparticles designed to possess a broader absorption spectrum to better match with that produced by the X-ray source. In their experiments, the size of A549 lung adenocarcinoma in mice treated with an IT injection of $1 \mathrm{mg} / \mathrm{kg}$ of nanoparticles plus $200 \mathrm{kV}$ X-ray radiation was at 22 days, approximately half the size of tumors in mice that received radiation alone. In this study, we obtained similar results with the Tio-GNPs; at 21 days post irradiation, tumor size was also approximately half that of the radiation-alone group. Le Duc et $\mathrm{al}^{41}$ studied gadolinium-based nanoparticles in $9 \mathrm{~L}$ gliosarcoma-bearing mice; with irradiation 20 minutes after IV injection of $40 \mathrm{mM}$ of nanoparticles, median survival time increased from 47 days in the radiation-alone group to 90 days. These nanoparticles can also be followed by magnetic resonance imaging.

Although similar radiosensitization effects and efficiencies have thus been reported in the literature for a variety of nanoparticles, due to the diverse nature of the experimental procedures and parameters (eg, animal model, efficacy evaluation method, radiation dose, and energy) it is not really possible to conclude which nanomaterial is superior as regards the radiosensitization efficiency. In theory, however, from among the abovementioned materials, gold almost always has the highest mass attenuation coefficient 
for X-rays in the $3 \mathrm{keV}$ to $\mathrm{MeV}$ range. Assuming similar numbers of secondary electrons emitted per unit of photon energy absorbed, then for the abovementioned nanomaterials, the radiosensitization efficiency of GNPs may be expected to be the highest. ${ }^{17,42}$

In the clinic, chemotherapeutic drugs are currently administered by CED. However, the endoscopic injection of therapeutic agents has only been applied in treating vesicoureteral reflux, esophageal tumor, and gastric cancer. ${ }^{20-23}$ It is therefore conceivable that upon further development, this route of injection could be applied to the direct injection of GNPs into early-stage colorectal tumors. Low-energy photons are necessary to reach maximum radioenhancement by GNPs, ${ }^{5,8-10,17}$ but, in practice, treatments with such radiation are problematic. Owing to their limited penetration depth in soft tissue, low-energy photons are only used in the clinic for a small number of diseases located at or near the surface of the body, such as melanomas, and it is very difficult to translate their use to most other cancer treatments. However, colorectal cancer could benefit from such a treatment. Certain colorectal cancers, dependent on stage, location, and age of the patient, can be treated by contact X-ray radiotherapy using the $50 \mathrm{kV}$ X-ray Papillon 50 technique, which introduces an X-ray applicator inside the rectum to deliver high-dose radiation directly to colorectal tumors. Depending on the tumor, node, and metastasis stage of the tumor, patients will receive three fractions of a total dose of 50 Gy for T1 patients, or higher if the tumor staging is higher. ${ }^{19}$ The energy spectrum of the Papillon $50 \mathrm{X}$-rays is similar to that of the X-ray source used in our study (Figure 1). In the clinic, the long-term control of T1N0 stage is $90 \%$ and that of $\mathrm{T} 2 \mathrm{~N} 0$ is $80 \%$, but it is only $50 \%$ for early T3. ${ }^{19}$ Based on our results, these numbers could be improved if GNPs were delivered by endoscopic IT injection to the tumor before irradiation.

\section{Conclusion}

IT injection of small Tio-GNPs, combined with an X-ray beam at an effective energy of $26 \mathrm{keV}$, can significantly reduce the growth of a colorectal tumor in a preclinical model.

\section{Acknowledgments}

We would like to thank Doctor AD Bass for helpful suggestions and corrections, François Lessard for providing the original data of the Therapax SXT 150 X-ray beam spectra, Doctor J Constanzo for the technical support in foci counting, and the Electron Microscopy and Histology Research Core of the Faculty of Medicine and Health Science at the Université de Sherbrooke for their electron microscopy services. This work was supported by the Canadian Institutes of Health Research (grant \# PPP-122899). Louis Gendron, Brigitte Guérin, Léon Sanche, and Benoit Paquette are members of the Centre de Recherche du CHUS supported by the Fonds de la Recherche du Québec - Santé.

\section{Disclosure}

The authors report no conflicts of interest in this work.

\section{References}

1. Chien CC, Wang CH, Hua TE, et al. Synchrotron X-ray synthesized gold nanoparticles for tumor therapy. AIP Conf Proc. 2007;879: 1908-1911.

2. Kong T, Zeng J, Wang X, et al. Enhancement of radiation cytotoxicity in breast-cancer cells by localized attachment of gold nanoparticles. Small. 2008;4(9):1537-1543.

3. Zhang X, Xing JZ, Chen J, et al. Enhanced radiation sensitivity in prostate cancer by gold-nanoparticles. Clin Invest Med. 2008;31(3): E160-E167.

4. Roa W, Zhang X, Guo L, et al. Gold nanoparticle sensitize radiotherapy of prostate cancer cells by regulation of the cell cycle. Nanotechnology. 2009;20(37):375101.

5. Hainfeld JF, Dilmanian FA, Zhong Z, Slatkin DN, Kalef-Ezra JA, Smilowitz HM. Gold nanoparticles enhance the radiation therapy of a murine squamous cell carcinoma. Phys Med Biol. 2010;55(11): 3045-3059.

6. Liu CJ, Wang CH, Chen ST, et al. Enhancement of cell radiation sensitivity by pegylated gold nanoparticles. Phys Med Biol. 2010; 55(4):931-945.

7. Chithrani DB, Jelveh S, Jalali F, et al. Gold nanoparticles as radiation sensitizers in cancer therapy. Radiat Res. 2010;173(6):719-728.

8. Hainfeld JF, Slatkin DN, Smilowitz HM. The use of gold nanoparticles to enhance radiotherapy in mice. Phys Med Biol. 2004;49(18): N309-N315.

9. Hébert EM, Debouttière PJ, Lepage M, Sanche L, Hunting DJ. Preferential tumour accumulation of gold nanoparticles, visualised by magnetic resonance imaging: radiosensitisation studies in vivo and in vitro. Int J Radiat Biol. 2010;86(8):692-700.

10. Bobyk L, Edouard M, Deman P, et al. Photoactivation of gold nanoparticles for glioma treatment. Nanomedicine. 2013;9(7):1089-1097.

11. Khlebtsov N, Dykman L. Biodistribution and toxicity of engineered gold nanoparticles: a review of in vitro and in vivo studies. Chem Soc Rev. 2011;40(3):1647-1671.

12. Hillyer JF, Albrecht RM. Gastrointestinal persorption and tissue distribution of differently sized colloidal gold nanoparticles. $J$ Pharm Sci. 2001;90(12):1927-1936.

13. Alkilany AM, Murphy CJ. Toxicity and cellular uptake of gold nanoparticles: what we have learned so far? J Nanopart Res. 2010;12(7): 2313-2333.

14. Cho WS, Cho M, Jeong J, et al. Acute toxicity and pharmacokinetics of $13 \mathrm{~nm}$-sized PEG-coated gold nanoparticles. Toxicol Appl Pharmacol. 2009;236(1):16-24.

15. Zhang XD, Wu D, Shen X, et al. Size-dependent radiosensitization of PEG-coated gold nanoparticles for cancer radiation therapy. Biomaterials. 2012;33(27):6408-6419.

16. Chen YS, Hung YC, Liau I, Huang GS. Assessment of the in vivo toxicity of gold nanoparticles. Nanoscale Res Lett. 2009;4(8):858-864.

17. Hainfeld JF, Dilmanian FA, Slatkin DN, Smilowitz HM. Radiotherapy enhancement with gold nanoparticles. J Pharm Pharmacol. 2008;60(8): 977-985.

18. Siegel R, Ma J, Zou Z, Jemal A. Cancer Statistics, 2014. Vol. 64. Toronto: Canadian Cancer Society; 2014. 
19. Gérard JP, Myint AS, Croce O, et al. Renaissance of contact X-ray therapy for treating rectal cancer. Expert Rev Med Devices. 2011;8(4): 483-492.

20. Moreira LS, Dani R. Treatment of granular cell tumor of the esophagus by endoscopic injection of dehydrated alcohol. Am J Gastroenterol. 1992;87(5):659-661.

21. Hirao M, Masuda K, Asanuma T, et al. Endoscopic resection of early gastric cancer and other tumors with local injection of hypertonic saline-epinephrine. Gastrointest Endosc. 1987;34(3):264-269.

22. Yasui T, Akita H, Sasaki S, Hayashi Y, Kohri K. Endoscopic injection of Teflon for correction of primary vesicoureteral reflux in children. Int J Urol. 1997;4(4):349-351.

23. Puri P, Chertin B, Velayudham M, Dass L, Colhoun E. Treatment of vesicoureteral reflux by endoscopic injection of dextranomer/hyaluronic acid copolymer: preliminary results. J Urol. 2003;170(4 pt 2):1541-1544.

24. Lessard F, Archambault L, Plamondon M, et al. Validating plastic scintillation detectors for photon dosimetry in the radiologic energy range. Med Phys. 2012;39(9):5308-5316.

25. Croce O, Hachem S, Franchisseur E, Marcie S, Gerard J, Bordy J. Contact radiotherapy using a $50 \mathrm{kV}$ X-ray system: evaluation of relative dose distribution with the Monte Carlo code PENELOPE and comparison with measurements. Radiat Phys Chem. 2012;81(6):609-617.

26. Xiao F, Zheng Y, Cloutier P, He Y, Hunting D, Sanche L. On the role of low-energy electrons in the radiosensitization of DNA by gold nanoparticles. Nanotechnology. 2011;22(46):465101.

27. Chang MY, Shiau AL, Chen YH, Chang CJ, Chen HH, Wu CL. Increased apoptotic potential and dose-enhancing effect of gold nanoparticles in combination with single-dose clinical electron beams on tumor-bearing mice. Cancer Sci. 2008;99(7):1479-1484.

28. Templeton AAC, Chen S, Gross SM, Murray RW, Hill C, Carolina N. Water-soluble, isolable gold clusters protected by tiopronin and coenzyme A monolayers. Langmuir. 1999;15(13):66-76.

29. Charest G, Paquette B, Fortin D, Mathieu D, Sanche L. Concomitant treatment of F98 glioma cells with new liposomal platinum compounds and ionizing radiation. J Neurooncol. 2010;97(2):187-193.

30. Gendron L, Lucido AL, Mennicken F, et al. Morphine and pain-related stimuli enhance cell surface availability of somatic delta-opioid receptors in rat dorsal root ganglia. $J$ Neurosci. 2006;26(3):953-962.
31. Tippayamontri T, Kotb R, Paquette B, Sanche L. Synergism in concomitant chemoradiotherapy of cisplatin and oxaliplatin and their liposomal formulation in the human colorectal cancer HCT116 model. Anticancer Res. 2012;32(10):4395-4404.

32. Schneider CA, Rasband WS, Eliceiri KW. NIH Image to ImageJ: 25 years of image analysis. Nat Methods. 2012;9(7):671-675.

33. Jain S, Coulter JA, Hounsell AR, et al. Cell-specific radiosensitization by gold nanoparticles at megavoltage radiation energies. Int J Radiat Oncol Biol Phys. 2011;79(2):531-539.

34. Chithrani DB. Intracellular uptake, transport, and processing of gold nanostructures. Mol Membr Biol. 2010;27(7):299-311.

35. Wang L, Liu Y, Li W, et al. Selective targeting of gold nanorods at the mitochondria of cancer cells: implications for cancer therapy. Nano Lett. 2011;11(2):772-780.

36. McMahon SJ, Hyland WB, Muir MF, et al. Biological consequences of nanoscale energy deposition near irradiated heavy atom nanoparticles. Sci Rep. 2011;1:18.

37. Misawa M, Takahashi J. Generation of reactive oxygen species induced by gold nanoparticles under X-ray and UV Irradiations. Nanomedicine. 2011;7(5):604-614.

38. Retif $\mathrm{P}$, Pinel S, Toussaint M, et al. Nanoparticles for radiation therapy enhancement: the key parameters. Theranostics. 2015;5(9):1030-1044.

39. Maggiorella L, Barouch G, Devaux C, et al. Nanoscale radiotherapy with hafnium oxide nanoparticles. Future Oncol. 2012;8(9):1167-1181.

40. Townley HE, Kim J, Dobson PJ. In vivo demonstration of enhanced radiotherapy using rare earth doped titania nanoparticles. Nanoscale. 2012;4(16):5043-5050.

41. Le Duc G, Miladi I, Alric C, et al. Toward an image-guided microbeam radiation therapy using gadolinium-based nanoparticles. ACS Nano. 2011;5(12):9566-9574.

42. Hubbell JH, Seltzer SM. Tables of X-Ray Mass Attenuation Coefficients and Mass Energy-Absorption Coefficients from $1 \mathrm{keV}$ to $20 \mathrm{MeV}$ for Elements $Z=1$ to 92 and 48 Additional Substances of Dosimetric Interest. Gaithersburg, MD: National Institute of Standards and Technology; 1996. 


\section{Supplementary material}

A

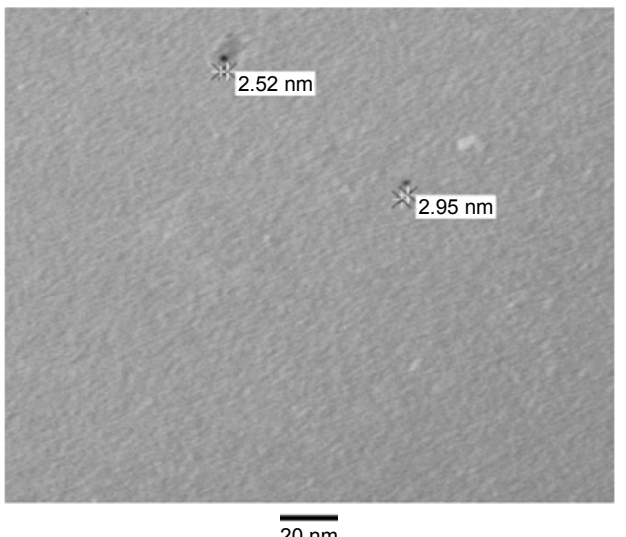

B

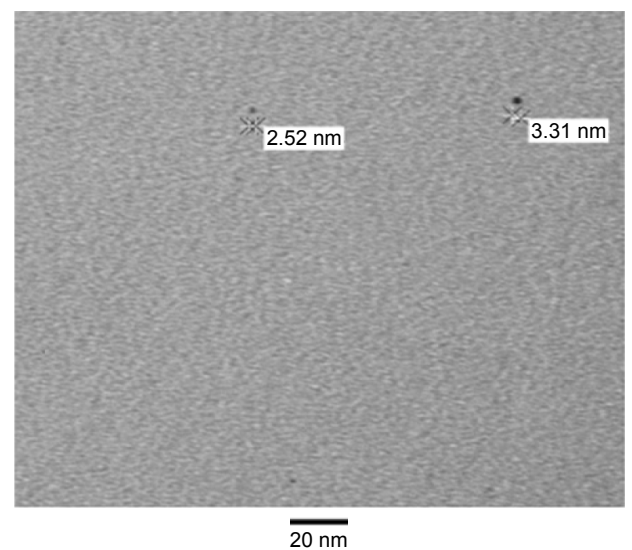

Figure SI Tio-GNPs in MEM at concentrations of $0.1 \mathrm{mg} / \mathrm{mL}(\mathbf{A})$ and $0.25 \mathrm{mg} / \mathrm{mL}$ (B) without FBS were visualized under TEM.

Notes: Magnification of SIA and B: 100,000x.

Abbreviations: FBS, fetal bovine serum; MEM, minimum essential medium; TEM, transmission electron microscopy; Tio-GNPs, tiopronin-coated gold nanoparticles.

\section{Publish your work in this journal}

The International Journal of Nanomedicine is an international, peerreviewed journal focusing on the application of nanotechnology in diagnostics, therapeutics, and drug delivery systems throughou the biomedical field. This journal is indexed on PubMed Central, MedLine, CAS, SciSearch $®$, Current Contents $\AA /$ Clinical Medicine,
Journal Citation Reports/Science Edition, EMBase, Scopus and the Elsevier Bibliographic databases. The manuscript management system is completely online and includes a very quick and fair peer-review system, which is all easy to use. Visit http://www.dovepress.com/ testimonials.php to read real quotes from published authors. 